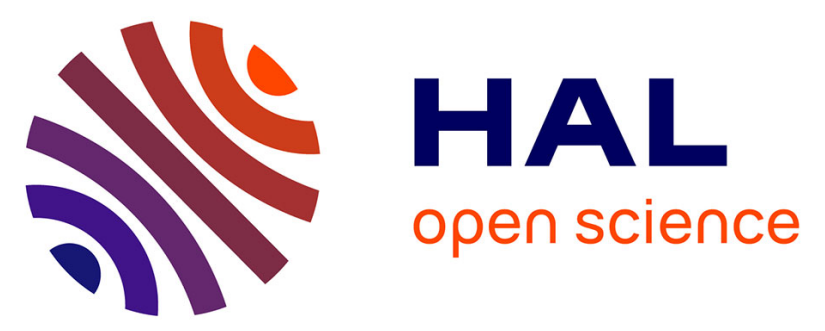

\title{
Contribution to the optimization of the autonomous photovoltaic solar systems with hybrid storage for loads with peak power with constraints of volume and loss of power supply probability
}

\author{
Guy Clarence Semassou, Abdel Deen Derrick Vital Dai Tometin, Roger \\ Ahouansou, Victorin Chegnimonhan, Tognon Clotide Guidi
}

\section{To cite this version:}

Guy Clarence Semassou, Abdel Deen Derrick Vital Dai Tometin, Roger Ahouansou, Victorin Chegnimonhan, Tognon Clotide Guidi. Contribution to the optimization of the autonomous photovoltaic solar systems with hybrid storage for loads with peak power with constraints of volume and loss of power supply probability. International Journal on Interactive Design and Manufacturing, 2020, 10.1007/s12008-020-00643-2 . hal-02501018

\author{
HAL Id: hal-02501018 \\ https://hal.science/hal-02501018
}

Submitted on 1 Mar 2021

HAL is a multi-disciplinary open access archive for the deposit and dissemination of scientific research documents, whether they are published or not. The documents may come from teaching and research institutions in France or abroad, or from public or private research centers.
L'archive ouverte pluridisciplinaire HAL, est destinée au dépôt et à la diffusion de documents scientifiques de niveau recherche, publiés ou non, émanant des établissements d'enseignement et de recherche français ou étrangers, des laboratoires publics ou privés. 
2 Contribution to the optimization of the autonomous photovoltaic with constraints of volume and loss of power supply probability

\author{
Guy Clarence Semassou ${ }^{1,2} \cdot$ Abdel Deen Derrick Vital Dai Tometin ${ }^{1,2}$ (D) Roger Ahouansou ${ }^{1,2}$. \\ Kouamy Victorin Chegnimonhan ${ }^{4} \cdot$ Tognon Clotide Guidi $^{1,3}$
}

\title{
Abstract
}

The storage of energy is a fundamental aspect in the performance and the lifespan of the autonomous photovoltaic solar systems. The batteries with lead-acid are the most widespread technology of storage, because of their great availability, their low cost and their weak maintenance. They are generally failing because of certain defects such as: the stratification, sulphating, short-circuits, oxidation... These various defects strongly affect the lifespan of the batteries and thus the lifetime cost of the solar system. The appearance of these defects is for most of the time related to a non-optimal dimensioning of the system which does not take into account the starting peak power of certain electrical appliance. Indeed, the taking into account of these peak powers generate an oversizing of the batteries, consequently of the photovoltaic field and thus a very significant investment. To answer these problems, we proposed in this work a method of optimization of the autonomous solar systems by integrating ultracapacitors to meet the requirement in peak power. A program of optimization was developed in Matlab for this purpose, simulations were also done under Simulink to explore the advantages of the integration of ultracapacitors in the element of storage of an autonomous PV system with various profiles of load. The program of optimization has a step of time able to collect the fluctuations of the load and profiles of solar radiation and generates the best orientation according to the site so that the photovoltaic panel generates the maximum annual power. The program also makes it possible to determine the financial economy carried out by exploiting the Hybrid System of Storage with ultracapacitors and proposes various combinations of panels, batteries and ultracapacitors compared to LVD limit fixed with the lifetime cost and the LPSP corresponding. The management system of energy for the complete system was studied with imposed constraint the full charge of ultracapacitors between the peak powers.

\section{Keywords Optimization · Lifetime cost · PV solar system · Ultracapacitor}

\section{List of symbols}

$\mathrm{E}_{\text {cap }} \quad$ Energy requirement of the supercondensator

(J)

$\mathrm{V}_{\mathrm{a}} \quad$ Maximum tension of operation of the supercondensator
$\mathrm{V}_{\mathrm{b}} \quad$ Minimal tension of operation of the supercondensator

$N_{\text {CapSer }} \quad$ Number of series ultracapacitors

$N_{\text {CapPar }} \quad$ Number of parallel ultracapacitors

$C_{\text {Cap }} \quad$ Nominal ultracapacitor capacitance

\footnotetext{
Guy Clarence Semassou

Clarence.semassou@gmail.com

Abdel Deen Derrick Vital Dai Tometin

derricktometin@gmail.com

Roger Ahouansou

gnankis@yahoo.fr

Kouamy Victorin Chegnimonhan

victorin.chegnimonhan@gmail.com

Tognon Clotide Guidi

guidi65@mail.ru
}

1 Laboratory of Energetics and Applied Mechanics (LEMA), University of Abomey-Calavi, 01 BP 2009 Cotonou, Benin

2 Laboratory of Thermophysical Characterization of Materials and Energy Appropriation (LABO - C. T. M. A. E.), University of Abomey-Calavi, 01 BP 2009 Cotonou, Benin

3 Laboratory Processes and Technology Innovation (LaPIT), University Institute of Technology Lokossa, Lokossa University, BP 133 Lokossa, Benin

4 Laboratory of Thermokinetics, (LTN) - CNRS, UMR 6607, BP 50609, 44306 Nantes, France

\begin{tabular}{|l|l|l|l|l|}
\hline Journal : Large 12008 & Article No : 643 & Pages : 11 & MS Code : 643 & Dispatch : 13-1-2020 \\
\hline
\end{tabular}




$\begin{array}{ll}C_{\text {CapReq }} & \begin{array}{l}\text { Required capacitance of the ultracapacitor } \\ \text { bank }\end{array} \\ \text { Vcap } & \text { Ultracapacitor voltage } \\ \text { NBattPar } & \text { Number of parallel batteries } \\ \text { NBattSer } & \text { Number of series batteries } \\ \text { VSys } & \text { System operating voltage } \\ V_{\text {Batt }} & \text { Battery rated voltage } \\ \text { Ah } & \text { Nominal battery capacity } \\ V_{\text {Batt }} & \text { Battery rated voltage } \\ V_{\text {Sys }} & \text { System operating voltage } \\ E_{\text {Batt }} & \text { Available battery energy } \\ S O C_{\text {Limit }} & \text { Battery SOC limit } \\ T & \text { Optimisation horizon } \\ \mathrm{PPV}_{\text {Storage }} & \text { PV panel output power } \\ P_{\text {Load }} & \text { Storage power } \\ \mathrm{N}_{\mathrm{i}} & \text { Load power } \\ \mathrm{CI}_{\mathrm{i}} & \text { Number of component } \mathrm{i} \\ \mathrm{CR}_{\mathrm{i}} & \text { Initial investment cost } \\ \mathrm{CMR}_{\mathrm{i}} & \text { Replacement cost } \\ \mathrm{PWA}_{\mathrm{i}} & \text { Cost of maintenance and repair of component i } \\ \mathrm{K}_{\mathrm{i}} & \text { Annual payment present worth factors } \\ \mathrm{y}_{\mathrm{i}} & \text { Single payment present worth factors } \\ \mathrm{L}_{\mathrm{i}} & \text { Numbers of replacements of component } \mathrm{i} \\ \text { ir } & \text { Lifetime of component i } \\ R_{v} & \text { Real interest rate } \\ & \text { Project's lifetime } \\ & \end{array}$

\section{Abbreviations \\ DOA Days of autonomy \\ LVD Low voltage disconnect \\ SOC State of charge \\ LPSP Loss of power supply probability \\ PV Photovoltaic \\ IEEE Institute of Electrical and Electronic Engineers \\ GSM Global System for Mobile Communication \\ ASECNA Agency of the safety of air navigation in \\ Africa and Madagascar \\ VRLA Valve regulated lead acid \\ LCC Life cyćle cost}

\section{Introduction}

The importance attached to optimization is increased for the autonomous generators of renewable energy, because the safety of a connection to the national network for the backup supply does not exist. A certain number of different methods are used for optimization of the intermittent autonomous generators. These methods include intuitive analytical methods and approaches of simulation of system [1].

A dimensioning method of a PV generator is described in the guide of the IEEE for dimensioning of panels and batteries in the autonomous photovoltaic systems [2]. The number of required photovoltaic panels is based on the solar radiation, the ratio network/load, the losses of the system and the load. If the load is constant, the solar radiation of the most unfavorable month is used in calculations. If the load varies, the most unfavorable case is selected like month with weakest ratio network/load. The number of necessary batteries is given according to the days of autonomy (DOA), by supposing that the photovoltaic generator does not provide any power.

Lagorse et al. [3] developed a method of optimization for a PV system of lighting with storage of hydrogen and battery. Methodology suggested uses an approach in two stages to determine the optimal solution. Initially a genetic algorithm is used to find a tendency of convergence; the value obtained starting from the genetic algorithm is used like starting point for an algorithm simplex. The objective is to minimize the cost on cycle of life of the system. The parameters taken into account during optimization are the power of the PV and the fuel cell, the angle of inclination of the PV system, the capacity of the battery, the fuel cell of starting and stop and the state of charge SOC of the battery. The current and the tension of the battery were not taken into account during the process.

Ekren and Ekren [4] carried out an optimization based on the simulation of a system wind-PV with storage of battery for a mobile station of communication GSM and for a domestic profile. Optimization was carried out with various profiles of load and auxiliary energy costs. Simulations are carried out with software ARENA and Opt-Quest. OptQuest requires a maximum and minimum number of components to enter for optimization to carry out.

Yang et al. [5] developed a methodology of dimensioning of an autonomous hybrid system wind-PV with storage of battery, based on the genetic algorithms. Optimization is carried out by taking account of the loss of probability of power supply (LPSP) and of the annualized cost of the system. Methodology describes the number of PV panels, batteries and wind mills as well as the angle of inclination of the panels and the height of the wind mills. The genetic algorithm uses time data and models of components to seek the optimal solution. The initial values for each component are necessary for the process of optimization.

Borowy and Salameh [6] developed a methodology to dimension in an optimal way the combination of a park of batteries and a PV generator in a hybrid system wind-PV autonomous. Methodology used makes it possible to minimize the economic cost of the system while ensuring without interruption the cover of the requirements in electric power. In methodology, the size of the wind mill is defined, with an iterative approach used to determine the number of batteries and necessary PV panels according to constraint LPSP. Optimization was carried out for each $1 \mathrm{~h}$ of typical day of each month.

\begin{tabular}{|l|l|l|l|l|}
\hline Journal : Large 12008 & Article No : 643 & Pages : 11 & MS Code : 643 & Dispatch : 13-1-2020 \\
\hline
\end{tabular}


Seeling-Hochmuth [7] jointly optimized the strategy of size and control for the hybrid systems, wind-PV, coupled with batteries with an auxiliary diesel generator. Optimization is carried out in two stages, the principal algorithm treats dimensioning of the system while the second subsystem treats optimization of control. For the size of selected system, the limits of control are adjusted to minimize the objective function subjected to constraints of exploitation, for example to minimize the cost of the system. The result of the process is an optimized configuration system and a strategy of control for the application and the site given.

The methods of optimization discussed in the literature make the average of the powers generated and consumption on an hourly basis to dimension the components of the solar system. The use of the average time data is satisfactory when in fact the requirements in energy are taken into account. However, the amplitude of the peaks of power is attenuated when it is realized on an hourly basis. Consequently, when we consider the effects of the peaks power on the system of storage, shorter temporal periods are necessary to collect the effects of the peaks power on the tension of the battery. Optimization by taking account peaks of power constitutes the principal objective of our research. In addition to that, we propose a method to correctly size the combination of the battery and the supercondensator in order to avoid the excessive costs of the system while having a constraint on the volume of the system.

\section{Materials and methods}

\subsection{Adopted profiles of consumption}

A certain number of profiles of load were developed to analyze the method of optimization under variable conditions. The profiles of load used were developed to represent a peak, an impulse and a domestic profile of load. The profile of peak load was developed to represent the starting of an engine with D.C. current. The current necessary to the initial starting of the engine is definitely higher than the current necessary to maintain the engine in steady operation. Typically, the inrush current of the engine could be six times the current in steady operation [8].The profile of peak load has a power peak of $200 \mathrm{~W}$ and the power continues is of approximately $32 \mathrm{~W}$.The engine is used during 45 min every hour, as illustrated on Fig. 1a, the profile of load being repeated daily over the period of optimization.

A profile of load of impulse is the second developed to evaluate the method. The load of impulse functions during $200 \mathrm{~s}$ over $250 \mathrm{~s}$ with a power of high impulse of $50 \mathrm{~W}$ and a basic power lower by $10 \mathrm{~W}$ the cyclic report/ratio of the impulses is 0.5 with one $20 \mathrm{~s}$ period. The profile of load is illustrated on Fig. 1b and functions uninterrupted.

The domestic profile of load was used to examine the method of optimization under a variable profile of load. The profile of domestic load annual describes on Fig. 2 is considered for our study.

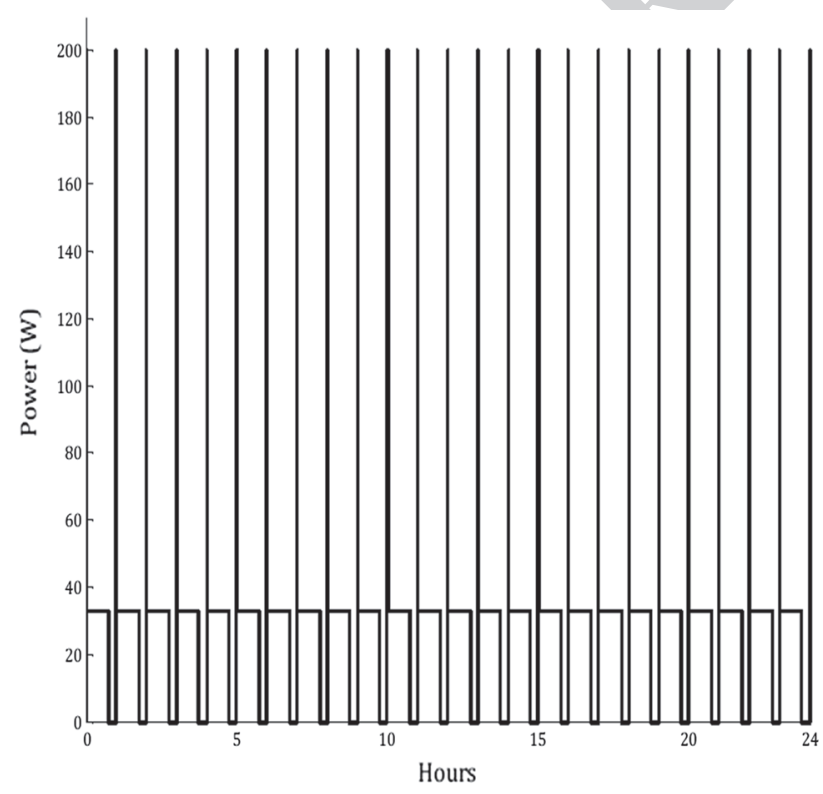

a Profile of daily maximum load

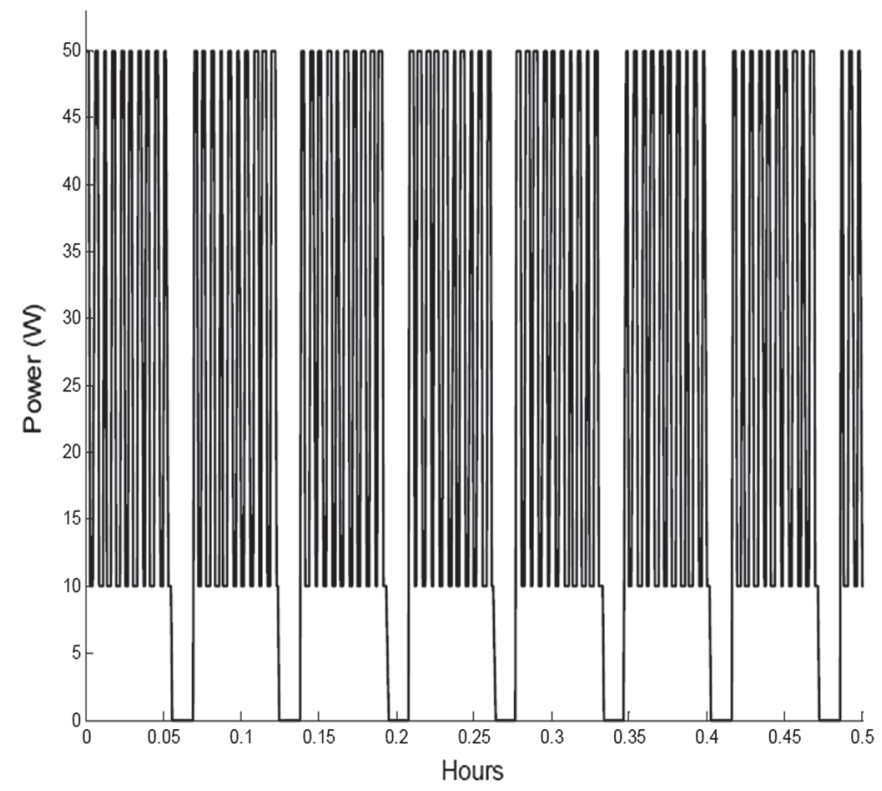

b Profile of load of impulse

Fig. 1 a Profile of daily maximum load. b Profile of load of impulse 


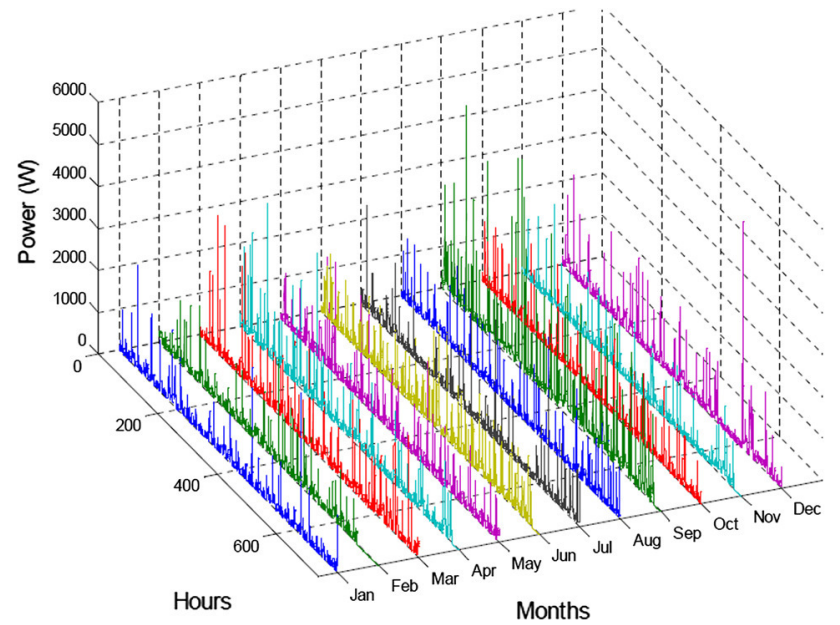

Fig. 2 Profile of domestic load

The profile has variable peaks of power occurring each day.

\subsection{Variation of the sunning and the temperature according to time}

The program of optimization developed requires the solar radiation on a horizontal level and the ambient temperature like entries to generate the power of maximum exit of PV panels over the duration of optimization. As the solar radiation varies during the year, a profile of annual solar radiation was obtained from a point located at Benin, precisely in
Cotonou. The data weather of the ASECNA were considered. Figure $3 \mathrm{a}$, b give respectively a chart of the solar radiation and ambient temperature recorded on the site.

\subsection{Description of the energy system}

The studied system includes various elements whose photovoltaic solar panels, the controller of load MPPT, the system of storage of energy (battery VRLA), the supercondensator, the controller of load for hybrid storage, and load (Fig. 4).

\subsection{Modeling}

\subsubsection{Model of determination of the numbers minimal and maximum of panels}

In autonomous PV systems, PV panels are the only source of generation of energy.

Consequently, PV panels must be able to generate the energy minimum required by the power consumption of the loads by taking account of the energy losses of PV system. As the power produced by the photovoltaic generator varies throughout the year, it exists a compromise between the increase in the number of photovoltaic panels and the increase in the system of storage, which feeds the load during the periods of weak or any solar radiation. To find the quantity optimal of panels photovoltaic to feed the load throughout the year with a System with Hybrid Storage, the number of photovoltaic panels varies between minimal and maximum. The minimal number of photovoltaic panels required to fulfill the
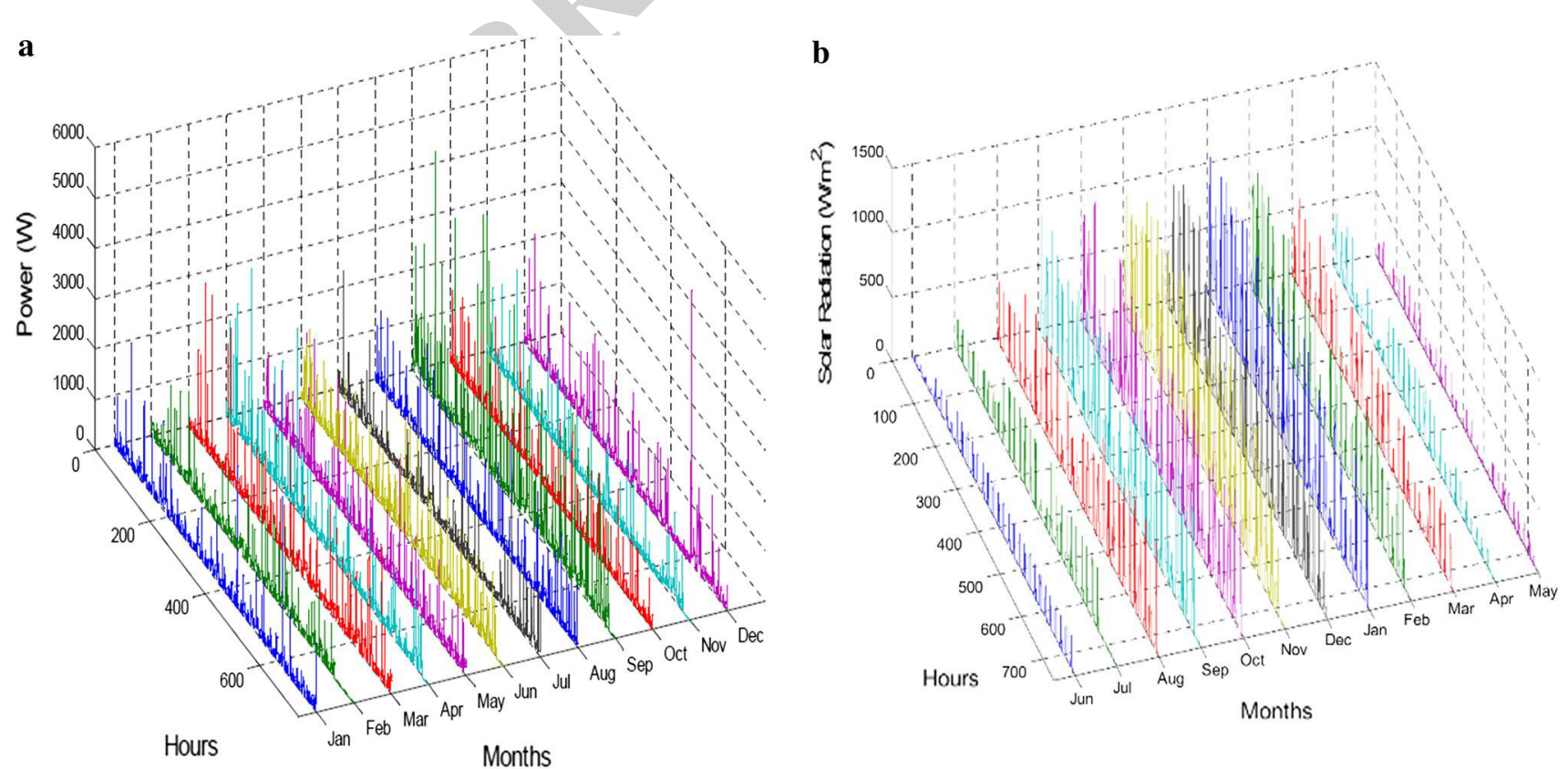

Fig. 3 annual Profile of a solar radiation, b ambient temperature at Cotonou 
Fig. 4 Configuration of autonomous photovoltaic system with hybrid storage

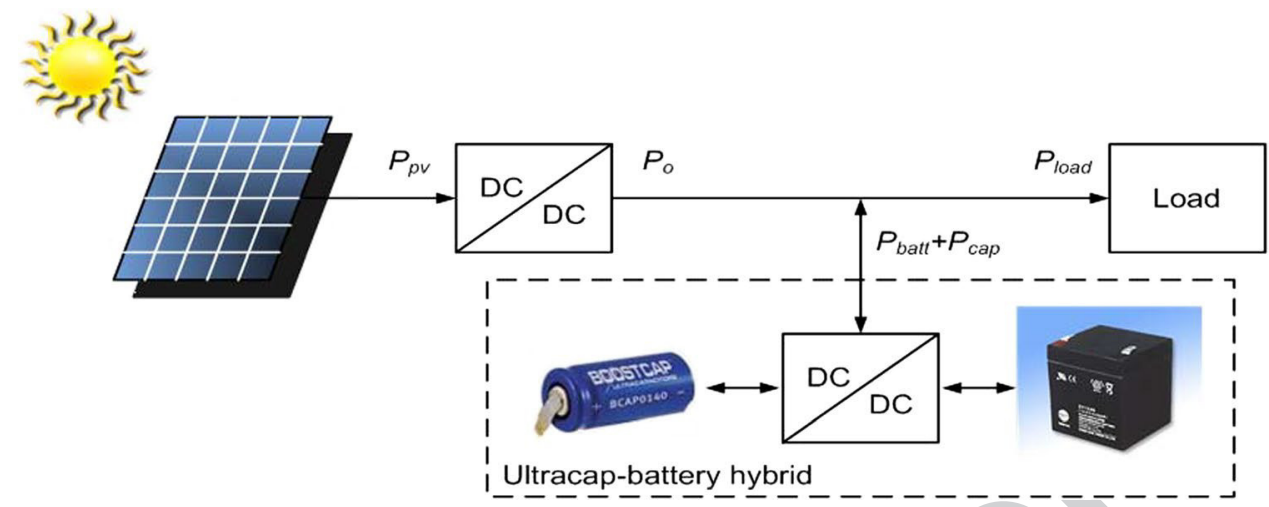

requirement of annual load, is calculated according to (1) per one duration of optimization 1 year.

$N_{P V \min }=\frac{\int_{1}^{8760} P_{\text {Load }}}{\int_{1}^{8760} P_{P V \max }}$

$N_{P V \max }=\frac{\max \int_{1}^{24} P_{\text {Load }}(\text { jour })}{\min \int_{1}^{24} P_{P V \max }(\text { jour })}$

where the day varies from 1 to 365 , so that the program analyzes each day of the year

\subsubsection{Model of capacity of the supercondensator}

In the System with Hybrid Storage, the park of supercondensator is used to provide the needs for power of point to the load which discharges the system from storage with a low average power provided by the bench of batteries. The necessary capacity of the park of supercondensators is calculated starting from the equation of energy of (3)

$C_{\text {CapReq }}=\frac{2 E_{c a p}}{V_{a}^{2}-V_{b}^{2}}$

where $\mathrm{E}_{\mathrm{cap}}$ Energy requirement of the supercondensator (J), $\mathrm{V}_{\mathrm{a}}$ Maximum tension of operation of the supercondensator, $\mathrm{V}_{\mathrm{b}}$ Minimal tension of operation of the supercondensator.

The number of supercondensators series-connected and in parallel can be obtained respectively by (4) and (5) by using the capacity calculated into (3) on the basis of maximum and minimum value of $\mathrm{E}_{\text {cap }}$.

$N_{\text {CapSer }} \geq \frac{V_{a}}{V_{\text {Cap }}}$

$N_{\text {CapPar }} \geq \frac{C_{C a p R e q} N_{\text {CapSer }}}{C_{\text {Cap }}}$

\subsubsection{Model of storage of the batteries}

257

The park of batteries is optimized by taking account of PV field and the capacity of the park of supercapacitors. The profile of charge/discharge of the System with Hybrid Storage is adjusted by using the profile of the supercapacittor to obtain the profile of charge/discharge park of batteries. The number of batteries series-connected is calculated according to (6):

$N_{\text {BattSer }}=\frac{V_{\text {Sys }}}{V_{\text {Batt }}}$

The determination of the number of batteries connected in parallel to increase the capacity of the battery is more complicated. The supplied energy of the batteries and the reduction of capacity due to the current of discharge are taken into account. The energy of the battery accessible in the System to Hybrid Storage depends on the SOC limit defined in the system and is determined by (7):

$E_{\text {Batt }}=V_{\text {Batt }} A h_{\text {cap }}\left(1-S O C_{\text {limit }}\right)$

By this method, the load and the discharge day labourer of the energy of the battery are compared to calculate the number of consecutive days where the battery is insufficiently charged. Consequently, in this situation, the contribution of the photovoltaic field and the bench of supercondensators to the load is taken into account, which reduces the initial size of the bench of batteries. The initial number of batteries in parallel is calculated from (8)

$N_{\text {BattPar }}=\left(\frac{E_{\max }}{E_{\text {Batt }}}\right) \times N_{j}$

\begin{tabular}{|l|l|l|l|l|}
\hline Journal : Large 12008 & Article No : 643 & Pages : 11 & MS Code : 643 & Dispatch : 13-1-2020 \\
\hline
\end{tabular}




\subsubsection{Loss of power supply probability (LPSP)}

The LPSP is the probability that a loss of supply energy occurs, which means that PV system and the system of storage of energy are not able to feed the load when it is needed.

Consequently, it is the fraction of the load which cannot be fed for the period of operation, going from 0 to 1 [1].The LPSP is calculated by (9)

$L P S P=\frac{1}{T} \int_{1}^{T}\left(\left(P_{P V}+P_{\text {Storage }}\right)<P_{\text {Load }}\right)$

when the LPSP is equal to 1 , the request is never satisfied and a redimensioning of the system is necessary. A LPSP equal to 0 means that the request is satisfied constantly, which, according to the criticality of the load, can involve an oversizing of the system with an increased cost.

\subsubsection{Economic model based on the concept of cost on cycle of life}

The function of optimization consists in minimizing the cost on cycle of life of the system. The lifespan of each component of the system must be given in the calculation of the cost. According to the chart of the manufacturer, the photovoltaic panels have one lifespan 20 years, which corresponds to the lifespan of the system [9].

The supercondensators are not replaced because they have one lifespan higher than 500,000 cycles [10].To determine the number of replacements of necessary battery throughout the lifespan of the system, a model of lifespan of the battery was built-in in the process of optimization. The model of battery is an energy model of flow based on the model used in the program of optimization Homer [11].

The number of replacements necessary for the battery during the lifespan of the system is given by comparing the annual throughput of the battery and the capacity of flow of the battery on the cycle of life (10).

$N_{R B}=\min \left(\frac{E_{B d e f}}{E_{r}}, C V_{B}\right)$

Life cycle cost (LCC) includes the value of the initial investment, the cost of replacing the component, the cost of maintenance and repair and the cost of downtime. For a component of the system I, the economic cost of the life cycle (during 25 years) can be expressed by the following equation [12-14]:

$L C C_{I}=N_{i}\left(C_{i}+C R_{i} \cdot K_{i}+C M R_{i} \cdot P W A\left(i r, R_{v}\right)\right)$

with:
$K_{i}=\sum_{n=1}^{y_{i}} \frac{1}{(1+i r)^{n l_{i}}}$

$y_{i}=\left(\frac{R_{v}}{L_{i}}\right)-1$, if $\mathrm{R}_{\mathrm{v}}$ is dividable to $\mathrm{L}_{\mathrm{i}} y_{i}=\left(\frac{R_{v}}{L_{i}}\right)$, if $\mathrm{R}_{\mathrm{v}}$ is not dividable to $\mathrm{L}_{\mathrm{i}}$

$P W A\left(i r, R_{v}\right)=\frac{(1+i r)^{R_{v}}-1}{i r(1+i r)^{R_{v}}}$

where $\mathrm{N}_{\mathrm{i}}$ is the number of component $\mathrm{i}, \mathrm{CI}_{\mathrm{i}}$ is the initial investment cost, $\mathrm{CR}_{\mathrm{i}}$ is the replacement cost, $\mathrm{CMR}_{\mathrm{i}}$ is the cost of maintenance and repair of component i. PWA and $\mathrm{K}_{\mathrm{i}}$ are annual and single payment present worth factors, respectively. $\mathrm{y}_{\mathrm{i}}$ and $\mathrm{L}_{\mathrm{i}}$ are the numbers of replacements of component $i$ and its lifetime. ir is the real interest rate, $R_{v}$ is the project's lifetime.

The total economic cost of the life cycle of the system can then be deduced:

$C_{\text {total }}=\sum_{i} L C C_{i}$

The price of PV panel, the battery and the supercapacitor is 200 euros, 70 euros and 45 euros respectively.

\subsection{Method of optimization used}

A program is conceived to optimize autonomous PV system with hybrid storage with supercapacitor. The function-objective of the program consists in minimizing the economic cost on cycle of life of the system with different constraint from volume and probability of loss of power. The program analyzes the possible angles of inclination of PV panel and calculates the angle which makes it possible to receive the maximum of radiation solar during the year. The program of optimization has like step of time the second, able to collect the peaks of power of the load and the fluctuations of the profiles of solar radiation.

The program also makes it possible to determine the financial economy carried out by exploiting the Hybrid System of Storage to supercapacitor and proposes various combinations of panels, batteries and supercapacitors compared to limit $L V D$ fixed with the cost on cycle of life and the corresponding level of cover in energy.

The various models previously benches were implemented under Matlab for the optimal dimensioning of the hybrid system, the calculation of the cost on cycle of life and the illustration of the level of load of the battery for each profile of load. The diagram of optimization developed is as follows (Fig. 5).

The management auditor of energy for the complete sys- $\mathbf{A Q 3}_{3}$ tem was studied with like imposed constraint the refill of the supercondensator between the points of power. 


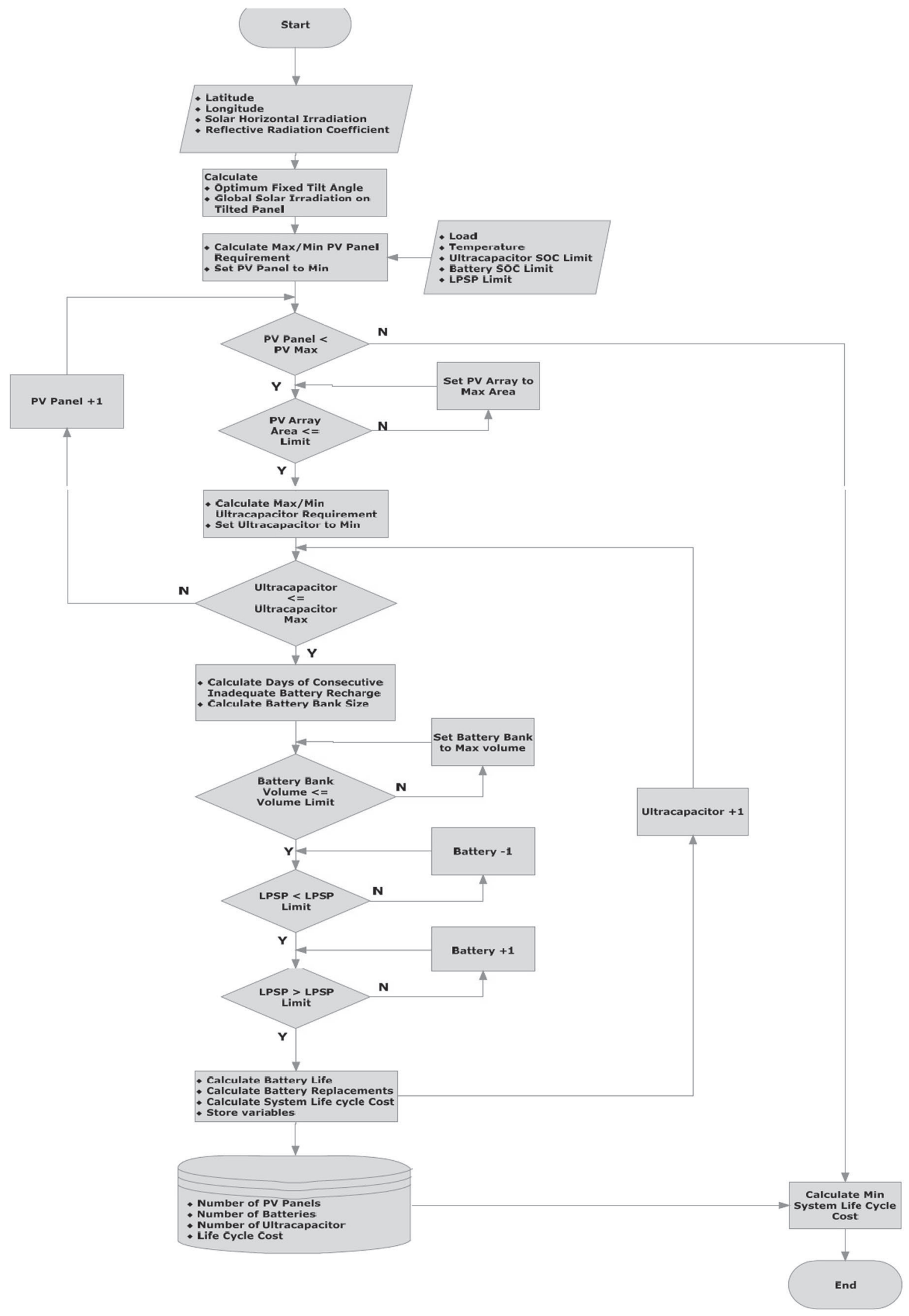

Fig. 5 Optimization methodology

\begin{tabular}{|l|l|l|l|l|}
\hline Journal : Large 12008 & Article No : 643 & Pages : 11 & MS Code : 643 & Dispatch : 13-1-2020 \\
\hline
\end{tabular}


Table 1 Controls system of storage of the battery

\begin{tabular}{ll}
\hline Condition & Action \\
\hline$\left(\boldsymbol{P}_{\text {mppt }}=\boldsymbol{P}_{\text {Load }}\right)$ & $I_{\text {Bat }}=0$ \\
$\left(\boldsymbol{P}_{\text {mppt }}>\boldsymbol{P}_{\text {Load }}\right) \&\left(\boldsymbol{B a t}_{\text {SOC }} \geq 100 \%\right)$ & $I_{\text {Load }}=I_{p v}+I_{\text {Bat }}$ \\
& DumpEnergy $=P_{\text {mppt }}-P_{\text {Load }}$ \\
& $I_{\text {Load }}=I_{p v}+I_{\text {Bat }}-$ DumpEnergy \\
$\left(\boldsymbol{P}_{\text {mppt }}>\boldsymbol{P}_{\text {Load }}\right) \&\left(\right.$ Bat $\left._{\text {SOC }}<100 \%\right)$ & $I_{\text {Bat }}=\left(P_{\text {Load }}-P_{\text {mppt }}\right) / V_{\text {sys }}$ \\
& $I_{\text {Load }}=I_{p v}+I_{\text {Bat }}$ \\
$\left(\boldsymbol{P}_{\text {mppt }}<\boldsymbol{P}_{\text {Load }}\right) \&\left(\right.$ Bat $_{\text {SOC }}$ & $I_{\text {Bat }}=\left(P_{\text {Load }}-P_{\text {mppt }}\right) / V_{\text {sys }}$ \\
$>$ Bat $\left._{\text {SoCLim }}\right)$ & $I_{\text {Load }}=I_{p v}+I_{\text {Bat }}$ \\
Else & $I_{\text {Bat }}=P_{\text {mpt }} / V_{\text {sys }}$ \\
& $I_{\text {Load }}=0$ \\
\hline
\end{tabular}

Table 2 Controls hybrid system of storage

\begin{tabular}{|c|c|}
\hline Condition & Action \\
\hline$\left(\boldsymbol{P}_{\text {mppt }}=\boldsymbol{P}_{\text {Load }}\right) \&\left(\right.$ Ucap $\left._{\text {SOC }}<100 \%\right) \&\left(\right.$ Bat $_{\text {SOC }}>$ Bat $\left._{\text {SOCLim }}\right)$ & $\begin{array}{l}I_{\text {Bat }}=B_{\text {lim }} \\
I_{\text {Ucap }}=-B_{\text {lim }} \\
I_{\text {Load }}=I_{p v}+I_{\text {Bat }}+I_{\text {Ucap }}\end{array}$ \\
\hline$\left(\boldsymbol{P}_{\text {mppt }}=\boldsymbol{P}_{\text {Load }}\right) \&\left(\right.$ Ucap $\left._{\text {SOC }}>100 \%\right) \mid\left(\boldsymbol{P}_{\text {mppt }}=\boldsymbol{P}_{\text {Load }}\right) \&\left(\right.$ Bat $_{\text {SOC }} \leq$ Bat $_{\text {SOCLim }}$ & $\begin{array}{l}I_{\text {Bat }}=0 \\
I_{\text {Ucap }}=0 \\
I_{\text {Load }}=I_{p v}+I_{\text {Bat }}+I_{\text {Ucap }}\end{array}$ \\
\hline$\left(\boldsymbol{P}_{\text {mppt }}>\boldsymbol{P}_{\text {Load }}\right) \&\left(\boldsymbol{U c a p}_{\text {SOC }}<100 \%\right)$ & $\begin{array}{l}I_{\text {Bat }}=0 \\
I_{\text {Ucap }}=\left(P_{\text {Load }}-P_{\text {mppt }}\right) / V_{\text {sys }} \\
I_{\text {Load }}=I_{p v}+I_{\text {Bat }}+I_{U c a p}\end{array}$ \\
\hline$\left(\boldsymbol{P}_{\text {mppt }}>\boldsymbol{P}_{\text {Load }}\right) \&\left(\right.$ Bat $\left._{\text {SOC }}<100 \%\right) \&\left(\boldsymbol{U c a p}_{\text {SOC }} \geq 100 \%\right)$ & $\begin{array}{l}I_{\text {Bat }}=\left(P_{\text {Load }}-P_{\text {mppt }}\right) / V_{\text {sys }} \\
I_{\text {Ucap }}=0 \\
I_{\text {Load }}=I_{p v}+I_{\text {Bat }}+I_{\text {Ucap }}\end{array}$ \\
\hline$\left(\boldsymbol{P}_{m p p t}>\boldsymbol{P}_{\text {Load }}\right) \&\left(\right.$ Bat $\left._{\text {SOC }} \geq 100 \%\right) \&\left(\boldsymbol{U c a p}_{\text {SOC }} \geq 100 \%\right)$ & $\begin{array}{l}I_{\text {Bat }}=0 \\
I_{\text {Ucap }}=0 \\
\text { DumpEnergy }=P_{m p p t}-P_{\text {Load }} \\
I_{\text {Load }}=I_{p v}+I_{\text {Bat }}+I_{\text {Ucap }}-\text { DumpEnergy }\end{array}$ \\
\hline $\begin{array}{l}\left(\boldsymbol{P}_{\text {mppt }}<\boldsymbol{P}_{\text {Load }}\right) \&\left(\text { Bat }_{\text {SOC }}>\text { Bat }_{\text {SOCLim }}\right) \&\left(\text { Ucap }_{\text {SOC }}>\text { Ucap }_{\text {SOCLim }}\right) \mid \\
\left(\boldsymbol{I}_{\text {storage }} \leq \text { Bat }_{\text {lim }}\right) \&\left(\boldsymbol{U c a p}_{\text {SOC }}<100 \%\right)\end{array}$ & $\begin{array}{l}I_{\text {Bat }}=B_{\text {lim }} \\
I_{\text {Ucap }}=\left(\left(P_{\text {Load }}-P_{\text {mppt }}\right) / V_{\text {sys }}\right)-B_{\text {lim }} \\
I_{\text {Load }}=I_{p v}+I_{\text {Bat }}+I_{\text {Ucap }}\end{array}$ \\
\hline $\begin{array}{l}\left(\boldsymbol{P}_{\text {mppt }}<\boldsymbol{P}_{\text {Load }}\right) \&\left(\text { Bat }_{\text {SOC }}>\text { Bat }_{\text {SOCLim }}\right) \&\left(\text { Ucap }_{\text {SOC }}>\text { Ucap }_{\text {SOCLim }}\right) \& \\
\left(\boldsymbol{I}_{\text {storage }} \leq \boldsymbol{B a t}_{\text {lim }}\right) \&\left(\boldsymbol{U c a p}_{\text {SOC }} \geq 100 \%\right)\end{array}$ & $\begin{array}{l}\left.I_{\text {Bat }}=\left(P_{\text {Load }}-P_{\text {mppt }}\right) / V_{\text {sys }}\right) \\
I_{\text {Ucap }}=0 \\
I_{\text {Load }}=I_{p v}+I_{\text {Bat }}+I_{\text {Ucap }}\end{array}$ \\
\hline$\left(\boldsymbol{P}_{\text {mppt }}<\boldsymbol{P}_{\text {Load }}\right) \&\left(\right.$ Bat $_{\text {SOC }}>$ Bat $\left._{\text {SOCLim }}\right) \&\left(\boldsymbol{U c a p}_{\text {SOC }}>\boldsymbol{U c a p}_{\text {SOCLim }}\right) \&\left(\boldsymbol{I}_{\text {storage }}>\right.$ Bat $\left._{\text {lim }}\right)$ & $\begin{array}{l}I_{\text {Bat }}=\text { Bat }_{\text {lim }} \\
I_{\text {Ucap }}=\left(\left(P_{\text {Load }}-P_{\text {mpt }}\right) / V_{\text {sys }}\right)-B_{\text {lim }} \\
I_{\text {Load }}=I_{p v}+I_{\text {Bat }}+I_{\text {Ucap }}\end{array}$ \\
\hline$\left(\boldsymbol{P}_{\text {mppt }}<\boldsymbol{P}_{\text {Load }}\right) \&\left(\right.$ Bat $_{\text {SOC }}>$ Bat $\left._{\text {SOCLim }}\right) \&\left(\boldsymbol{U c a p}_{\text {SOC }} \leq \boldsymbol{U c a p}_{\text {SOCLim }}\right) \&\left(\boldsymbol{I}_{\text {storage }} \leq\right.$ Bat $\left._{\text {lim }}\right)$ & $\begin{array}{l}I_{\text {Bat }}=B a t_{\text {lim }} \\
I_{\text {Ucap }}=\left(\left(P_{\text {Load }}-P_{\text {mpt }}\right) / V_{\text {sys }}\right)-B_{\text {lim }} \\
I_{\text {Load }}=I_{p v}+I_{\text {Bat }}+I_{\text {Ucap }}\end{array}$ \\
\hline$\left(\boldsymbol{P}_{\text {mppt }}<\boldsymbol{P}_{\text {Load }}\right) \&\left(\right.$ Bat $_{\text {SOC }}>$ Bat $\left._{\text {SOCLim }}\right) \&\left(\boldsymbol{U c a p}_{\text {SOC }} \leq \boldsymbol{U c a p}_{\text {SOCLim }}\right) \&\left(\boldsymbol{I}_{\text {storage }}>\right.$ Bat $\left._{\text {lim }}\right)$ & $\begin{array}{l}\left.I_{\text {Bat }}=\left(P_{\text {Load }}-P_{\text {mppt }}\right) / V_{\text {sys }}\right) \\
I_{\text {Ucap }}=0 \\
I_{\text {Load }}=I_{p v}+I_{\text {Bat }}+I_{\text {Ucap }}\end{array}$ \\
\hline$\left(\boldsymbol{P}_{\text {mppt }}<\boldsymbol{P}_{\text {Load }}\right) \&\left(\right.$ Bat $_{\text {SOC }} \leq$ Bat $\left._{\text {SOCLim }}\right) \&\left(\right.$ Ucap $_{\text {SOC }}>$ Ucap $\left._{\text {SOCLim }}\right)$ & $\begin{array}{l}I_{\text {Bat }}=0 \\
I_{\text {Ucap }}=\left(P_{\text {Load }}-P_{\text {mppt }}\right) / V_{\text {sys }} \\
I_{\text {Load }}=I_{p v}+I_{\text {Bat }}+I_{\text {Ucap }}\end{array}$ \\
\hline Else & $\begin{array}{l}I_{\text {Bat }}=0 \\
I_{\text {Ucap }}=-P_{\text {mppt }} / V_{\text {sys }} \\
I_{\text {Load }}=I_{p v}+I_{\text {Bat }}+I_{\text {Ucap }}\end{array}$ \\
\hline
\end{tabular}

The algorithm of optimization for the control of the simple system of storage and hybrid storage is presented at the following tables (Tables 1, 2).

\section{Results and discussions}

\subsection{Peak load without constraints}

The results of optimization are presented at Table 3, indicating to the number of photovoltaic panels, of batteries, supercondensators as well as the cost on cycle of life of the system and the consecutive days of insufficient refill undergone by the battery during the year. The optimal fixed angle so that the site produces the maximum annual power of the 
Table 3 System of hybrid storage versus optimized for various limits SOC

\begin{tabular}{|c|c|c|c|c|c|c|c|c|c|}
\hline \multirow[t]{2}{*}{ SOC limit } & \multicolumn{5}{|c|}{ Hybrid storage system } & \multicolumn{4}{|c|}{ Storage system with only battery } \\
\hline & $\mathrm{N}_{\mathrm{PV}}$ & $\mathrm{N}_{\mathrm{BAT}}$ & Ncap & Cost $(€)$ & $\begin{array}{l}\text { Jours } \\
\text { InadChar }\end{array}$ & $\mathrm{N}_{\mathrm{PV}}$ & $\mathrm{N}_{\mathrm{BAT}}$ & Cost $(€)$ & $\begin{array}{l}\text { Days } \\
\text { Inad- } \\
\text { Char }\end{array}$ \\
\hline 20 & 27 & 14 & 1 & 10,525 & 7 & 29 & 16 & 11,400 & 7 \\
\hline 30 & 29 & 14 & 1 & 10,925 & 7 & 33 & 15 & 11,850 & 7 \\
\hline 40 & 31 & 15 & 1 & 11,675 & 7 & 31 & 19 & 12,850 & 7 \\
\hline 50 & 33 & 16 & 1 & 12,425 & 7 & 33 & 21 & 13,950 & 7 \\
\hline 60 & 33 & 20 & 1 & 13,825 & 7 & 33 & 25 & 15,350 & 7 \\
\hline 70 & 34 & 26 & 1 & 16,125 & 7 & 34 & 32 & 18,000 & 7 \\
\hline 80 & 56 & 23 & 1 & 19,475 & 4 & 52 & 34 & 22,300 & 4 \\
\hline 90 & 83 & 29 & 1 & 26,975 & 4 & 75 & 50 & 32,500 & 2 \\
\hline
\end{tabular}

of under load for one prolonged period of time. The lead sulphate crystals are usually transformed into lead during the process of load. If the battery is not sufficiently reloaded, certain lead sulphate crystals remain on the plates. Finally, soft the lead sulphate crystals become hard and act like an insulating layer preventing the battery from receiving the load. The capacity of the battery is reduced and possibly a cellular short-circuit can occur.

The stratification caused by an insufficient load of the battery occurs in drowned batteries lead-acid. It occurs when the heavier sulphuric acid in the electrolyte runs at the bottom of the case of the battery by leaving almost pure water on the top. Almost pure water at the top of the case of the battery is not a good conductive of electricity, for this reason, only the lower part of the plates for battery is available to conduct electricity reducing the capacity of the battery.

Oxidation occurs on the higher part of the plates causing corrosion. Corrosion involves permanent damage, reduced the performances of the battery and reduces the lifespan of the battery. Equalization and the gazage can help to prevent the stratification by agitating the electrolyte $[3,15]$.

The process of optimization was carried out during 1 year by holding account of the lifespan of the components during the calculation of the cost of the system. Consequently, because of the short lifespan of the battery, it proved more economic to increase the number of photovoltaic panels necessary to feed the load for the periods of weak solar radiation, generating an energy of discharge for the periods of high solar radiation. The optimal combination of the bench of batteries and PV system is such as the batteries are reloaded with full load during the major part of the year.

\subsection{Peak load with constraints of volume}

The Hybrid System of Storage with a SOC limit of $20 \%$ imposed on the park of batteries was examined for the restrictions of volume on the individual component in the system. The number of PV panels for this case was limited

\begin{tabular}{|l|l|l|l|l|}
\hline Journal : Large 12008 & Article No : 643 & Pages : 11 & MS Code : 643 & Dispatch : 13-1-2020 \\
\hline
\end{tabular}


to 15 , that is to say a reduction of 12 panels. The reduction of the number of photovoltaic panels leads to a number of consecutive days of insufficient refill of the battery passing with 8 , the number of batteries necessary to satisfy the SOC limit increasing to 40 . The reduction of the number of photovoltaic panels increases the need for storage for energy. The battery of the Hybrid System of Storage is increased to allow the food of the load for the long periods of weak solar radiation. When the number of photovoltaic panels is reduced, the quantity of energy produced during the year also decreases. The increase in the number of batteries necessary and their replacement cost throughout the lifespan of the system make pass the total cost to 17,225 euros. The minimal and maximum daily consumption of the battery during the year can be seen on Fig. 7a.

One second analysis of sensitivity limiting the number of seven batteries in the System of Hybrid Storage with a SOC limit of battery of $20 \%$ was also carried out. The limitation of the battery in the Hybrid System of Storage requires the installation of a larger photovoltaic generator, in order to generate the daily requirements in energy for the load, because the bench of batteries is not enough large to provide the load for one prolonged period. In this situation, the number of PV panels is almost doubled to 51, which changes the cost of the system to $12,875 €$. The great number of PV panels also increases the quantity of energy produced by the photovoltaic generator during a high solar radiation. The annual minimal daily maximum loading of the battery can be seen on Fig. 7b. The great number of photovoltaic panels brings back the bench of batteries to $100 \%$ of SOC during the major part of the year, but the reduction of the number of batteries means that the batteries are discharged on a level from weaker load. The comparison of the cost of the system with life of the two analyses of sensitivity highlights the impact of the battery on the cost on cycle of life because of the number of replacements of necessary batteries for this period.

\subsection{Peak load with LPSP constraint}

The size of the system and the cost on cycle of life can be reduced if the outputs were not critical and if a $L P S P$ higher than zero were taken into account. During the major part of the year, the batteries of the system are maintained on a level of load raised in the system of hybrid storage. If the system were authorized not to feed the load for a short period of time for prolonged periods of weak solar radiation which occur only twice during the year, the park of batteries could be reduced. The adjustment of the LPSP with $0.9132 \times 10^{-3}$ in the process of optimization for the system of hybrid storage with a SOC limit of $20 \%$ tiny room the cost of the system with $9825 €$. This is carried out by reducing the size of the battery. A pressure loss of approximately nine hours was observed for the period of weak solar radiation. The maximum and minimal daily SOC values of the battery for the hybrid system of storage are indicated on Fig. 8. To take a
470

471

472

473

474

475

476

477

478

479

480

481

482

483

484

485

486

487

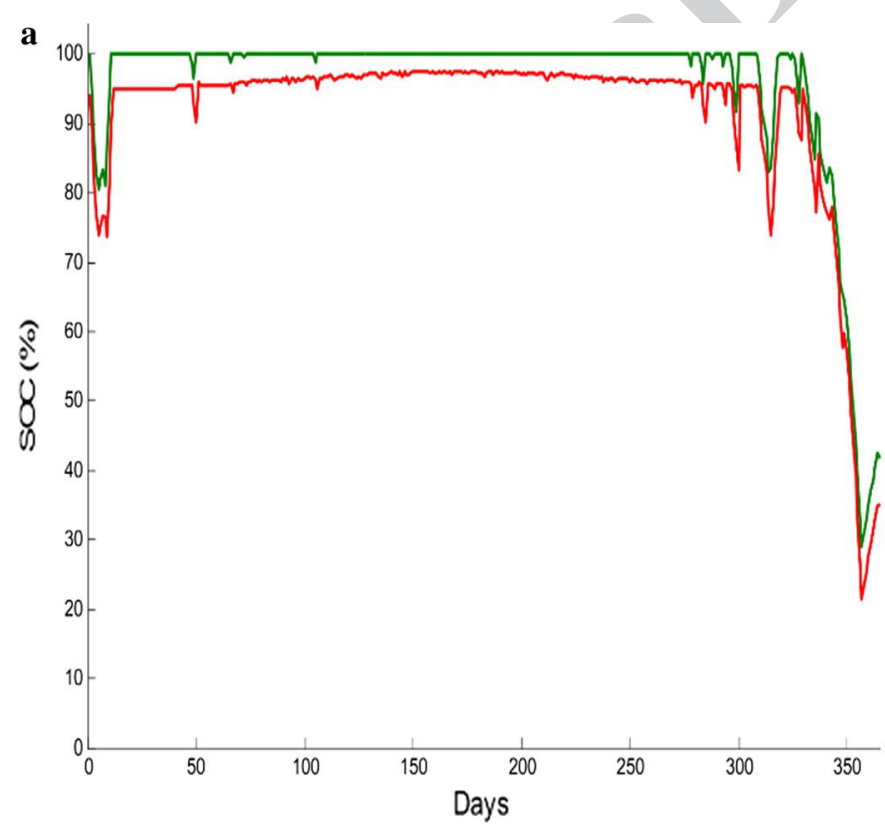

—Daily Max SOC — Daily Min SOC

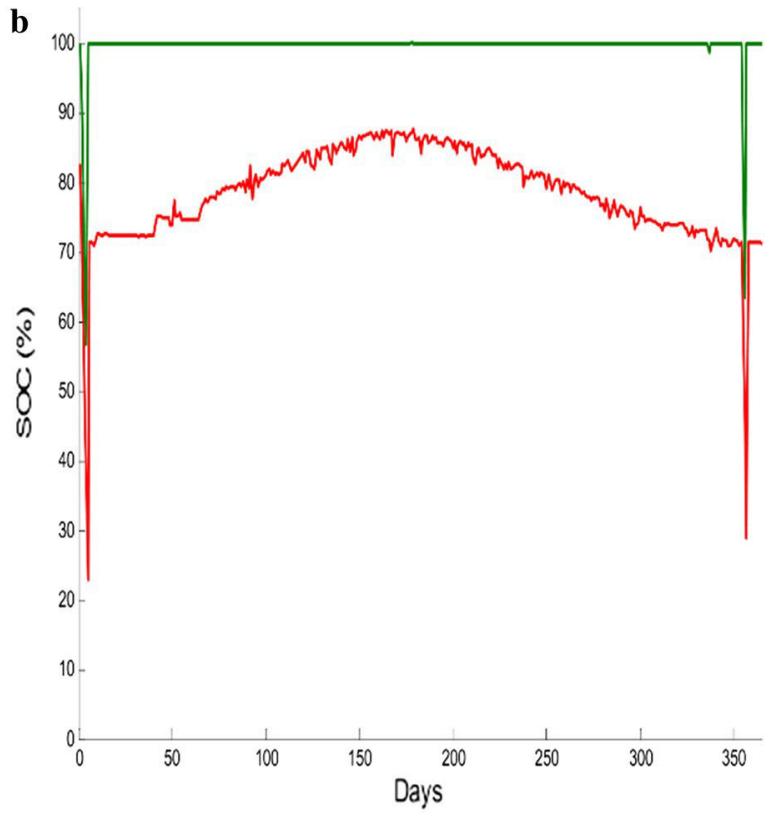

Daily Max SOC —Daily Min SOC

Fig. 7 maximum/minimum daily SOC of the battery (a) with PV field limited to 15 panels and SOC of $20 \%$ (b) with park of batteries limited to 7 batteries and SOC of $20 \%$

\begin{tabular}{|l|l|l|l|l|}
\hline Journal : Large 12008 & Article No : 643 & Pages : 11 & MS Code : 643 & Dispatch : 13-1-2020 \\
\hline
\end{tabular}




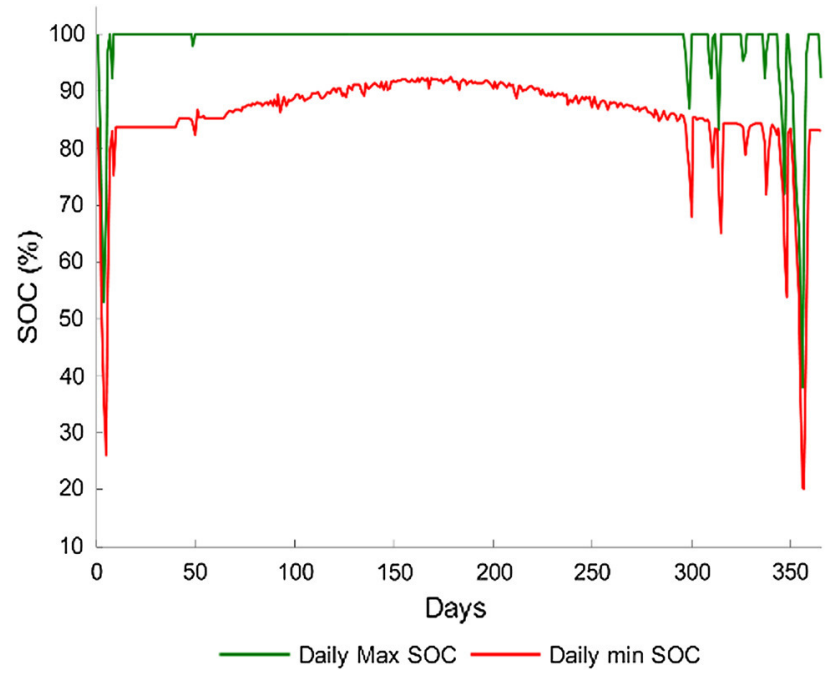

Fig. 8 Niveau de charge maximal/minimum quotidien de la batterie pour un système optimisé avec une limite de SOC de $20 \%$ et un LPSP de $0.9132 \times 10^{-3}$

greater limit of LPSP will more reduce the cost on cycle of life of the system to the detriment of a less reliable system.

\section{Conclusions}

The results shows that supercapacitors decrease losses in batteries keeping them at a good state of charge thanks to low-level discharges current. In most systems with battery storage, these are sized to support instant powers. In the presence of supercapacitors, this dimensioning will be done according to the average power to drop size of batteries without affecting normal operation of the system.

Supercapacitors improve the operation of batteries and so increase their lifespan and then reduce investment costs. Also, the fact that supercapacitors can be completely discharged and stored as is, makes their very interesting use for PV applications.

Results also shows that supercapacitors take in account peaks current and therefore relieve the batteries. In the case where these are placed in outside, the benefical role of supercapacitors is even greater since lead-acid batteries went very badly at low temperatures.

It should be noted that the efficiency of the converters is very low while it is impossible to make a reliable energy balance (losses in energy are greater than the energy provided by supercapacitors). In conclusion, these tests allow to show that supercapacitors allow optimal functioning of batteries, resulting in an increase in their service life.

In conclusion, to achieve the objectives, we explored the optimal design of autonomous photovoltaic solar systems with hybrid storage in accordance with the specifications.
It was necessary to apply knowledge in energy and industrial engineering. It was also necessary to integrate digital simulation into collaborative design environments in order to find the best candidate for design variables for each piece of equipment in the system. Throughout this approach, the objective of this research is achieved: reduce the risks in the decision-making design, optimize the choice in the preliminary design and develop optimal robust design methods for solar systems with hybrid storage.

\section{References}

1. Semassou, C.: AIDE A LA DECISION POUR LE CHOIX DE SITES ET SYSTEMES ENERGETIQUES ADAPTES AUX BESOINS DU BENIN. Université de Bordeaux, Thèse (2011)

2. IEEE Guide for Array and Battery Sizing in Stand-Alone Photovoltaic (PV) Systems, Standard 1562-2007 (2008)

3. Lagorse, J., Paire, D., Miraoui, A.: Sizing optimization of a stand-Alone street lighting system powered by a hybrid system using fuel Cell, PV and battery. Renew. Energy 34, 683-691 (2009)

4. Ekren, B.Y., Ekren, O.: Simulation based size optimization of a $\mathrm{PV} /$ wind hybrid energy conversion system with battery storage under various load and auxiliary energy conditions. Appl. Energy 86, 1387-1394 (2009)

5. Yang, H., Zhou, W., Lu, L., Fang, Z.: Optimal sizing method for stand-Alone hybrid solar-Wind system with LPSP technology by using genetic algorithm. Sol. Energy 82, 354-367 (2008)

6. Borowy, B.S., Salameh, Z.M.: Methodology for optimally sizing the combination of a battery bank and PV array in a wind/ PV hybrid system. IEEE Trans. Energy Convers. 11(2), 367-375 (1996)

7. Seeling-Hochmuth, G.C.: A combined optimisation concept for the design and operation strategy of hybrid-PV energy systems. Sol. Energy 61(2), 77-87 (1997)

8. Kaplanis, S.: The Design and Integration of Possible PV Configurations to Determine the Most Cost Effective System for a Household. University of Patra, Patras (2004)

9. Solar Panels 1 to 50 Watt Solar Panels/BP350U 50 W 12 V SolarAQ4 1 Panel. http://www.altestore.com/store, p 270

10. http://www.maxwell.com

11. http://www.homerenergy.com/documents/MicropowerSyste mModelingWithHomer.pdf

12. Khan, M.J., Iqbal, M.T.: Pre-feasibility study of stand-alone hybrid energy systems for applications in Newfoundland. Renew. Energy 30, 835-854 (2005)

13. Navaeefard, A., Moghaddas Tafreshi, S.M., Derafshian Maram, M.: Distributed energy resources capacity determination of a hybrid power system in electricity market. In: 25th International Power System Conference 10-E-EPM-2163, PSC (2010)

14. Dehghan, S., Kiani, B., Kazemi, A., Parizad, A.: Optimal Sizing of a Hybrid Wind/PV Plant Considering Reliability Indices, p. 56. World Academy of Sciences, Engineering and Technology, Paris (2009)

15. Cugnet, M., Dubarry, M., Tann, Liaw B.: Peukert's law of a lead acid battery simulated by a mathematical model. ECS Trans. 25(35), 223-233 (2010)

Publisher's Note Springer Nature remains neutral with regard to jurisdictional claims in published maps and institutional affiliations.

\begin{tabular}{|l|l|l|l|l|}
\hline Journal : Large 12008 & Article No : 643 & Pages : 11 & MS Code : 643 & Dispatch : 13-1-2020 \\
\hline
\end{tabular}




\begin{tabular}{|ll|}
\hline Journal: & $\mathbf{1 2 0 0 8}$ \\
Article: & $\mathbf{6 4 3}$ \\
\hline
\end{tabular}

\section{Author Query Form}

\section{Please ensure you fill out your response to the queries raised below and return this form along with your corrections}

Dear Author

During the process of typesetting your article, the following queries have arisen. Please check your typeset proof carefully against the queries listed below and mark the necessary changes either directly on the proof/online grid or in the 'Author's response' area provided below

\begin{tabular}{|c|c|c|}
\hline Query & Details Required & Author's Response \\
\hline AQ1 & $\begin{array}{l}\text { Kindly check and confirm whether the corresponding author affiliation is correctly } \\
\text { identified. }\end{array}$ & \\
\hline AQ2 & $\begin{array}{l}\text { Please check and confirm inserted citation of Tables } 1,2 \text { and Figures } 4 \text { and } 5 \text { are } \\
\text { correct. }\end{array}$ & \\
\hline AQ3 & $\begin{array}{l}\text { Figures: figure (5) is poor in quality as it looks fuzzy. Please supply a high-resolution } \\
\text { version of the said figure preferably in .tiff or .jpeg format with } 300 \text { dpi resolution. }\end{array}$ & \\
\hline AQ4 & Please check and confirm reference [9] is correct. & \\
\hline
\end{tabular}

\begin{tabular}{|l|l|l|l|l|}
\hline Journal : Large 12008 & Article No: $\mathbf{6 4 3}$ & Pages : $\mathbf{1}$ & MS Code : 643 & Dispatch : 13-1-2020 \\
\hline
\end{tabular}

